\title{
Complicated Meckel's diverticulum and therapeutic management
}

\author{
Varlık Erol, Tayfun Yoldaș, Samet Cin, Cemil Çalıșkan, Erhan Akgün, Mustafa Korkut
}

\section{ABSTRACT}

Department of General Surgery Ege University Faculty of Medicine, İzmir, Turkey

\section{Address for Correspondence Dr. Varlık Erol}

Department of General Surgery, Ege University Faculty of Medicine, İzir, Turkey Phone.: +90 2323904020 e-mail:

varlikerol@gmail.com

Received: 01.04 .2013

Accepted: 29.05 .2013

(C) Copyright 2013 by Turkish Surgical Association

Available online at www.ulusalcerrahidergisi.org
Objective: This study aimed to investigate the treatment options and compare patient management with the literature for patients operated on for an acute abdomen who had complications due to inflammation of the Meckel's diverticulum at our clinics.

Material and Methods: This study retrospectively evaluated 14 patients who had been operated on for acute abdomen and had been diagnosed with Meckel's diverticulitis (MD) in Ege University Medical Faculty Department of General Surgery, between October 2007 and October 2012.

Results: Fourteen patients with a diagnosis of Meckel's diverticulitis (MD) were retrospectively analyzed. Radiologically, the abdominal computer tomography showed pathologies compatible with mechanical intestinal obstruction, Meckel's diverticulitis and peridiverticular abscess, as well as detection of free air within the abdomen on direct abdominal X-ray. Among patients diagnosed with complicated Meckel's diverticuli (obstruction, diverticulitis, perforation) 10 patients had partial small bowel resection and end-to-end anastomosis ( $71.5 \%)$, three patients underwent diverticulum excision (21.4\%), and one patient underwent right hemicolectomy+ileotransversostomy (7.1\%).

Conclusion: Meckel's diverticulum is a vestigial remnant of an omphalomesenteric channel in the small bowel. It is a real congenital diverticular abnormality that contains all three layers of the small bowel. Surgical excision should be performed if Meckel's diverticulum is detected in order to avoid incidental complications such as ulceration, bleeding, bowel obstruction, diverticulitis or perforation. Meckel's diverticulitis does not have specific clinical and radiological findings. Delayed diagnosis can lead to lethal septic complications. Complications associated with Meckel's diverticulitis, especially if a definite diagnosis is not made during the preoperative period, should be considered in the differential diagnosis. In the presence of a complicated diverticulum the appropriate treatment should be emergent surgical intervention.

Key Words: Small bowel, Meckel's diverticulum, treatment

\section{INTRODUCTION}

Meckel diverticulum (MD) is the most common congenital abnormality of the gastrointestinal system. $M D$ is a true diverticulum containing all layers of bowel wall located in the ileum anti-mesenteric border. It results from non-closure of the omphalo-mesenteric canal, which is supposed to obliterate in the $5^{\text {th }}-7^{\text {th }}$ gestational weeks (1). Although first described by Fabricus Hildanus in 1598, the German anatomist Johann Friedrich Meckel defined this pathology embryological and named it in 1809 (2). The incidence within the general population is around $2 \%$ (3). It usually contains ileal mucosa, but there may be heterotopic gastric, pancreatic, duodenal or colonic mucosa (4). The most common ectopic tissue is gastric mucosa and the most common complication related to this ectopic tissue is lower gastrointestinal bleeding. Most cases remain asymptomatic, presenting to the clinics when complications occur. Only 3.7-6.4\% of patients with MD become symptomatic throughout their lifetime (5). Complications of Meckel diverticuli are intestinal obstruction, bleeding, diverticulitis, umbilical fistula, diverticular perforation, and cecal volvulus. This study aimed to investigate the treatment options and compare patient management with the literature for patients operated on for an acute abdomen who had complications due to inflammation of the Meckel's diverticulum at our clinics.

\section{MATERIAL AND METHODS}

This study retrospectively evaluated 14 patients who had been operated on for acute abdomen and had been diagnosed with Meckel's diverticulitis (MD) in Ege University Medical Faculty Department of General Surgery, between October 2007 and October 2012. Clinical symptoms, signs, laboratory and radiologic data were retrieved. 


\section{RESULTS}

The study group consisted of 9 male (64.2\%), and 5 female (35.8\%) patients. The mean age was 51.3. Two patients had free air within the abdomen on plain X-ray and one patient was pre-diagnosed with acute appendicitis, these patients did not have an abdominal computerized tomography (CT). CT scans on 11 patients revealed signs of perforation in one patient, mechanical intestinal obstruction in 4, mesenteric vascular disease in 1, Meckel diverticulum in 3, cecal wall thickening due to tumor in 1, sigmoid colon wall thickening and abscess in 1 patient. Ten patients had partial small bowel resection and end-to-end anastomosis, three patients underwent diverticulum excision, and one patient underwent right hemicolectomy + ileotransversostomy (Figure 1, 2) (Table 1). The intra-operative diagnoses of MD complications were diverticulum perforation in 10 patients, mechanical intestinal obstruction due to diverticulum in one and diverticulum invagination in 3 patients (Table 1). In the postoperative period, oral intake was not allowed and the patients were given intravenous hydration, naso-gastric tube decompression and fluid-electrolyte replacement therapy. The pathology evaluations were reported as "mucosal congestion, edema, hemorrhage and ischemic changes in patients with diverticulum". The histopathologic mean diverticular size was 4,6 $\mathrm{cm}(2-11 \mathrm{~cm})$. Histopathologic ectopic tissue revealed two gastric mucosa, 1 pancreatic tissue and no heterotopic focus in 5 patients. In six patients, the diverticulum mucosa could not be assessed due to necrosis and intense inflammation. Three patients (21.4\%) died with multi-organ failure and cardiopulmonary arrest. The remaining 11 (78.6\%) patients were discharged after an uneventful progress.

\section{DISCUSSION}

Congenital gastrointestinal abnormalities constitute $6 \%$ of all congenital abnormalities, and MD is the most common congenital abnormality of the gastrointestinal system (6). It results from non-union of the omphalo-mesenteric canal. The incidence in general population is $1-3 \%$, in autop-

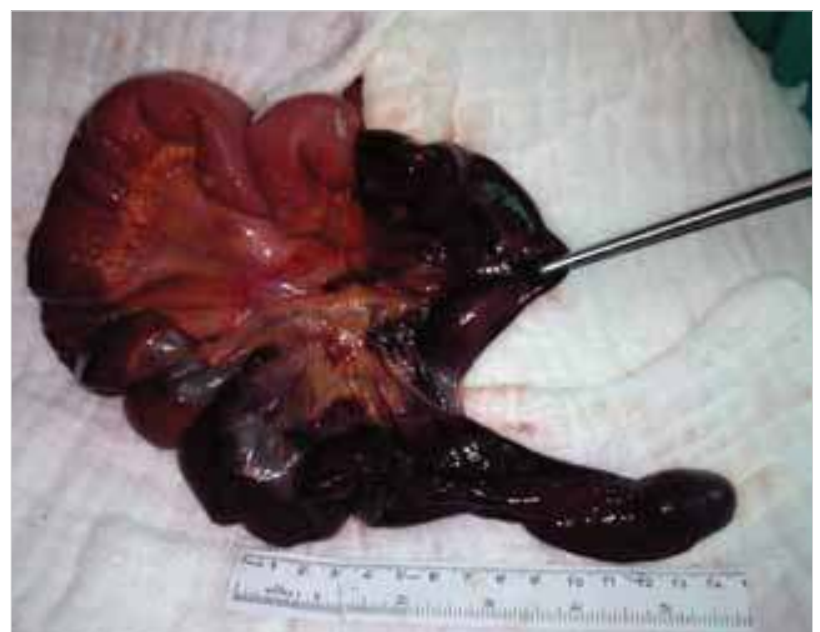

Figure 1. Peroperative view of Meckel diverticula causing invagination and secondary obstruction sy series this rate is reported as $0.14-4.5 \%$ (5). They usually remain asymptomatic. When symptomatic, they present as intestinal obstruction in pediatric patients and bleeding in adults. There is a male predominance. The male/female ratio was reported to be 3/1 in a study from Mayo including 1476 patients (7). In the present study, diverticulum was present in males twice more. The Mayo Clinic study stated that $16 \%$ of patients become symptomatic and $29 \%$ carry ectopic or abnormal tissues. Pathophysiologically, the fetal midgut receives nutrients from the yolk sac by vitelline canal during early embryonic life. This channel progressively narrows and diminishes by the $7^{\text {th }}$ week of gestation. When this channel does not completely obliterate vitelline duct abnormalities occur. They are usually located $40-60 \mathrm{~cm}$ proximal to ileocecal valve in the anti-mesenteric border. Diverticular size varies between 1-10 cm (8). Ectopic mucosa can be seen in 1/3 of patients, the most common being gastric mucosa. Gastric mucosa constitutes more than $60 \%$ of the ectopic tissue. The second common foci is pancreatic acinus, but Brunner glands, pancreas islands, colon mucosa, endometriosis and hepatobiliary tissue might also be seen (9). Bleeding usually results from peptic ulcer due to ectopic gastric mucosa. Incidentally recognized MD during surgery generally contains intestinal mucosa. Diverticuli containing gastric mucosa are more responsible for symptoms. The remaining ectopic tissue can be seen in the following rates; pancreatic tissue in $6 \%$, combination of pancreatic tissue and gastric mucosa $5 \%$, jejunal mucosa $2 \%$, Brunner gland $2 \%$ and combination of gastric and duodenal mucosa $2 \%$ (10).

Resection is recommended for treatment of complicated MD, whereas this issue is controversial for patients with incidental findings. In their epidemiologic study Cullen et al. (11) suggest routine resection to all incidental MD's under the age of 80 . On the other hand the Mayo Clinic study found that age under 50, male gender, diverticular length over $2 \mathrm{~cm}$ and diverticulum containing ectopic or abnormal tissue as factors related with symptoms, and diverticulum diameter and length/diameter

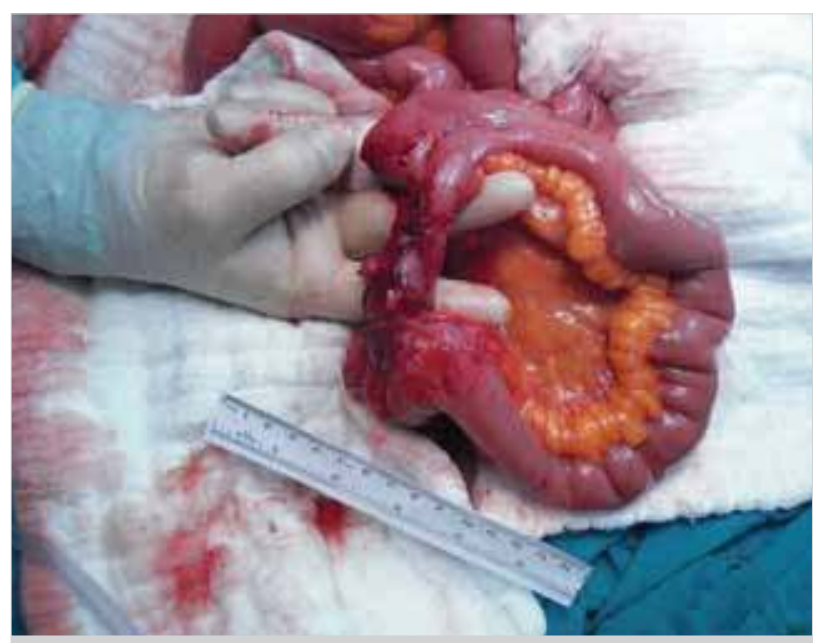

Figure 2. Peroperative view of Meckel diverticula causing adhesion and obstruction 
Table 1. Patient data

\begin{tabular}{|c|c|c|c|c|c|}
\hline Patient & Age & Gender & Diverticular complication & Operation & Mortality \\
\hline 1 & 31 & $\mathrm{~F}$ & Perforation & SBR, Mikulicz ileostomy & + \\
\hline 2 & 57 & M & Diverticula & Diverticulum & - \\
\hline 3 & 24 & $\mathrm{~F}$ & Perforation & SBR, end-to-end anastomosis & - \\
\hline 4 & 21 & M & Invagination & SBR, end-to-end anastomosis & - \\
\hline 5 & 70 & M & Perforation & Diverticulum & - \\
\hline 6 & 36 & M & Diverticula & SBR, end-to-end anastomosis & - \\
\hline 7 & 76 & M & Perforation & SBR, end-to-end anastomosis & + \\
\hline 8 & 19 & M & Perforation & SBR, end-to-end anastomosis & - \\
\hline 9 & 76 & $\mathrm{~F}$ & Perforation & SBR, end-to-end anastomosis & + \\
\hline 10 & 82 & M & Perforation & SBR, end-to-end anastomosis & - \\
\hline 11 & 36 & M & Perforation & Diverticulum & - \\
\hline 12 & 87 & M & Perforation & SBR, end-to-end anastomosis & - \\
\hline 13 & 36 & $\mathrm{~F}$ & Perforation & Right hemicolectomy & - \\
\hline 14 & 68 & $\mathrm{~F}$ & Diverticula & SBR, end-to-end anastomosis & - \\
\hline
\end{tabular}

ratio as irrelevant factors. They recommend resection in the presence of one out of these four factors. In the presence of one criteria the rate of becoming symptomatic is $17,2 \%$, two criteria $25,3 \%$, three criteria $42 \%$ and 4 criteria $70 \%$. Diverticular length in our study was $>2 \mathrm{~cm}$ in all cases (mean 4.6 $\mathrm{cm}$ ). Another area of debate is the role of simple diverticulectomy in asymptomatic MD treatment. If a mass of ectopic diverticular tissue is found at the base of the diverticulum, this diverticulum should be resected in a way not to leave any excess tissue. In cases where a mass is not palpable or uncomplicated diverticulum simple diverticulectomy is sufficient (7).

\section{CONCLUSION}

Complicated MD usually present with bleeding, intestinal obstruction or diverticuli, in this study most of the patients had perforation $(71,4 \%)$. The other complications were mechanical bowel obstruction related to the diverticulum (21.4\%) and invagination (7.2\%). Small bowel perforation carries high morbidity and mortality especially in elder patients with co-morbidities, requiring emergent surgical intervention, MD must be kept in mind for the differential diagnosis of perforations despite its rarity. Surgical options include diverticulectomy or segmentery bowel resection. The surgical treatment should be decided according to the patient's pathology intraoperatively.

Author Contributions: Concept - T.Y., V.E.; Design - T.Y., V.E.; Supervision - T.Y., V.E.; Funding - V.E., T.Y., S.C., C.Ç., E.A., M.K.; Data Collection and/or Processing - V.E., T.Y., S.C.; Analysis and/or Interpretation - V.E., T.Y., C.Ç., E.A., M.K.; Literature
Review - V.E., T.Y.; Writer - V.E., T.Y.; Critical Review - C.Ç., E.A., M.K.

Peer-review: Externally peer-reviewed.

Conflict of Interest: No conflict of interest was declared by the authors.

Financial Disclosure: The authors declared that this study has received no financial support.

\section{REFERENCES}

1. Peoples T, Lichtenberger ET, Dunn M. Incidental Meckel's diverticulectomy in the adults. Surgery 1995; 118: 649-652. [CrossRef]

2. Opitz JM, Schultka R, Gobbel L. Meckel on developmental pathology. Am J Med Genet A 2006; 140: 115-128. [CrossRef]

3. Synder CL. Meckel's Diverticulum.Ashcraft KW (Ed). In Pediatric Surgery. 3rd Edition, WB Saunders, 2000: 541-544.

4. Rosai J. Gastrointestinal Tract. In Surgical Pathology. 9th ed.Michael Houston. New York, Elsevier Inc, 2004: 714-715.

5. Piñero A, Martínez-Barba E, Canteras M, Rodriguez JM, Castellanos $G$, Parrilla P. Surgical management and complications of Meckel's diverticulum in 90 patients. Eur J Surg 2002; 168: 8-12. [CrossRef]

6. Uppal K, Tubbs RS, Matusz P, Shaffer K, Loukas M. Meckel's diverticulum: a review. Clin Anat 2011; 24: 416-422. [CrossRef]

7. Park JJ, Wolff BG, Tollefson MK, Walsh EE, Larson DR. Meckel diverticulum: the Mayo Clinic experience with 1476 patients. Ann Surg 2005; 241: 529-533. [CrossRef]

8. Groebli Y, Bertin D, Morel P. Meckel's Diverticulum in adults: Retrospective analysis of 119 cases and historical review. Eur J Surg 2001; 167: 518-524. [CrossRef]

9. Yahchouchy EK, Marano AF, Etienne JCF, Fingerhut AL. Meckel's Diverticulum. J Am Coll Surg 2001; 192: 658-662. [CrossRef] 
Erol et al.

Complicated Meckel's diverticulum

10. Elsayes KM, Menias CO, Harvin HJ, Francis IR. Imaging manifestations of Meckel's diverticulum. AJR Am J Roentgenol 2007; 189: 81-88. [CrossRef]
11. Cullen JJ, Kelly KA, Moir CR, Hodge DO, Zinsmeister AR, Melton LJ 3rd. Surgical management of Meckel's diverticulum. An epidemiologic, population-based study. Ann Surg 1994; 220: 564-569. [CrossRef] 